\title{
Mental Emotional Disorders in the Community
}

\author{
Warih Andan Puspitosari ${ }^{1 *}$ Shanti Wardaningsih ${ }^{2}$
}

\author{
${ }^{1}$ Psychiatric Medicine Department, School of Medicine, Faculty of Medicine and Health Sciences, Universitas \\ Muhammadiyah Yogyakarta \\ ${ }^{2}$ Psychiatric Nursing Department, School of Nursing, Faculty of Medicine and Health Sciences, Universitas \\ Muhammadiyah Yogyakarta \\ *Corresponding author. Email: warih.andan@umy.ac.id
}

\begin{abstract}
According to Indonesia Basic Health Research 2018, the prevalence of mental emotional disorders which is indicated by depression and anxiety symptoms reached $9.8 \%$ of the total households in Indonesia. Screening of mental emotional disorders in a population at risk needs to be done. Therefore, people with mental emotional disorders can be handled promptly and appropriately. The purpose of this study was to determine the prevalence of mental emotional disorders in risk community through screening in the community as well as to find the related factors. This research was a descriptive-analytic study with a cross-sectional method which was conducted from January to April 2019. The subjects of this study were 104 people taken from 4 NCD-integrated health care post (Posbindu PTM), in Kasihan 2 Community Health Centre, Bantul District, Special Region of Yogyakarta, Indonesia. Inclusion criteria were 18-59 years old, cooperative, and willing to participate in the study. Exclusion criteria included having a serious physical illness, disability, comorbidity with substance abuse, or other serious mental disorders. The screening applied a selfreporting questionnaire (SRQ) 20. The data was processed using a computer program, SPSS. Descriptive data were presented categorically using the distribution frequency of subjects' characteristics and percentages of mental emotional disorders. Bivariate analysis using the chi-square test was used to evaluate the correlation among characteristic factors of the subjects and mental emotional disorders. Most subjects were in the age of 41-50, female, unemployed, and high school graduate. A total of 29 people $(27.9 \%)$ of the subjects had mental emotional disorders, 45 people $(43.3 \%)$ were easily feeling tired, and 35 people $(33.7 \%)$ feel worried, tense, and anxious. There was one person who had a suicide idea. The factor associated with mental emotional disorders was the level of education (pvalue $=0.05)$. Mental emotional disorders were experienced by $27.9 \%$ of the subjects in this study with the most symptom was easily feeling tired. Screening of mental health disorders should be performed periodically in the community and primary care.
\end{abstract}

Keywords: mental emotional disorders, screening, $S R Q$, community, non-communicable disease

\section{INTRODUCTION}

The increasing number of mental health disorders have become global health concerns. According to 2001 world health report, mental and behavioral disorders were estimated to occur in $25 \%$ of people at any time in their lives. ${ }^{[1]}$ Mental emotional disorders are common disorders found in society. The Emotional disorder is a state of emotional change that as an individual continues to develop into a pathological state, it is necessary to anticipate as well as to maintain..$^{[2]}$ Mental emotional disorders can be noted from a variety of symptoms such as anxiety and depression. ${ }^{[3]}$ Anxiety and depression disorders are also common disorders that are often found in society. Depression is a frequent nuisance, resulting in disability and required high cost. ${ }^{[4]}$ Anxiety disorder is the most frequent disorder after depressive disorder.

Although various terms such as common mental disorders, emotional and behavioral disorders, or other terms are collectively used, in Indonesia the term mental emotional disorders is nationally used as it refers to the symptom of anxiety and depression screened using SRQ-
20 questionnaire. In this study, term of mental emotional disorders is used as well. According to basic health research in 2013, Indonesia has an increase in emotional disorders (symptoms of anxiety and depression) for $6 \%$, in which the most category was people of 15 years old. While in 2018, mental emotional disorder happened to $9.8 \%$ of the total households in Indonesia. ${ }^{[5] 6]}$

Most people with mental emotional disorders seek help in primary care, but are often unrecognized, so they do not get a proper treatment. ${ }^{[7]}$ Untreated mental emotional disorders will become severe, cause burden, and decrease productivity as well as the quality of life. Screening of mental emotional disorder is necessary to assist the early detection, so that people can get proper treatment and cure. Screening should be carried out in community with the risk of non-communicable disease in the integrated care post (Posbindu PTM). The facility is chosen for the research site because the risk of mental health is prone to the targeted community. The study was intended to determine the prevalence of mental emotional disorders as well as the related factors in the community through screening. 


\section{METHODS}

This study was a survey research to determine the prevalence of mental emotional disorders in society. This research applied a descriptive analytic study with a crosssectional design. Data collection was carried out from January to April 2019. The research site was in Kasihan 2 Community Health Centre, Bantul, Yogyakarta. Data were taken from participants in NCD-Integrated health care post (Posbindu PTM), Kasihan 2 Community Health Centre which already has 4 units of NCD-Integrated health care post in 4 areas. The population was residents aged 15-59. The inclusion criteria were 18-59 years old, cooperative, willing to participate in the study. The exclusion criteria included having serious physical illness or disability and having a history of substance abuse or other serious mental disorders. Research subjects voluntarily join the research with the consecutive sampling method.

The screening of mental emotional disorders used self-reporting questionnaires (SRQ) 20. This questionnaire is self-reported by the subjects. It contains 20 questions related to the issues that may have been bothering someone during the past 30 days. If the subject considers the question to be a problem he/she has experienced within the last 30 days, the answer is "yes", and vice versa. It is stated as mental emotional disorder if the respondent has at least 6 out of 20 questions. This questionnaire is for screening psychological problems, anxiety, and depression. Questions contain symptoms that are more directed to the symptoms of depression, anxiety, somatic, cognitive, and the symptoms of decreasing energy. ${ }^{[12]}$

The data were processed using the SPSS computer program, and analyzed in stages using univariate and bivariate analyzes. Univariate analysis was used to provide an overview of the characteristics of each research variable using frequency and percentage distributions. The description of the subject characteristics is divided into the characteristics of the subject, namely age, gender, level of education, occupation, marital status, and the number of children. Bivariate analysis aimed to determine the factors associated with mental emotional disorders. Bivariate analysis used the chi-square test or Fisher exact test.

\section{RESULT}

\subsection{Subject Characteristics}

The research subjects consisted of 104 people who met the inclusion and exclusion criteria with characteristics as shown in Table 1.
Table 1. The characteristics of the subjects

\begin{tabular}{|c|c|c|}
\hline Characteristics & Frequency & Percentage \\
\hline \multicolumn{3}{|l|}{ Age (years old) } \\
\hline$<20$ & 2 & 1,9 \\
\hline $21-30$ & 9 & 8,7 \\
\hline $31-40$ & 29 & 27,9 \\
\hline $41-50$ & 48 & 46,2 \\
\hline $51-60$ & 16 & 15,4 \\
\hline \multicolumn{3}{|l|}{ Occupation } \\
\hline Unemployed & 59 & 56,7 \\
\hline Employed & 45 & 43,3 \\
\hline \multicolumn{3}{|l|}{ Sex } \\
\hline Male & 6 & 5,8 \\
\hline Female & 98 & 94,2 \\
\hline \multicolumn{3}{|l|}{ Education } \\
\hline Elementary & 9 & 8,7 \\
\hline Junior High & 26 & 25 \\
\hline High School & 55 & 52,9 \\
\hline College/University & 14 & 13,5 \\
\hline \multicolumn{3}{|l|}{ Marital Status } \\
\hline Not Married & 4 & 3,8 \\
\hline Married & 97 & 93,3 \\
\hline Widow/er & 3 & 2,9 \\
\hline \multicolumn{3}{|l|}{ Salary (IDR) } \\
\hline$<1.500 .000$ & 63 & 60,6 \\
\hline $1.500 .000-3.500 .000$ & 32 & 30,8 \\
\hline$>3.500 .000$ & 9 & 8,7 \\
\hline \multicolumn{3}{|l|}{ Number of Children } \\
\hline 0 & 7 & 6,7 \\
\hline 1 & 28 & 26,9 \\
\hline 2 & 52 & 50,0 \\
\hline 3 & 14 & 13,5 \\
\hline 4 & 3 & 2,9 \\
\hline
\end{tabular}

Based on table 1, it is known that most of the subjects were in 41-50 years old, as many as 48 people (46.2\%). Subjects under 20 years old were the smallest group (1.9\%). More than half of the subjects $(56.7 \%)$ are not working. Female subjects were the dominant participants (94.2). Only 5.8\% was male. At most, the level of subject education was high school education for $52.9 \%$. Almost all subjects $(93.3 \%)$ were married. The household salary of the subjects was mostly less than the minimum wage. Half of the subjects (50\%) had 2 children.

\subsection{Subjects' Emotional Mental Disorders}

Emotional mental disorders were assessed by a total score of more than 5, which means the answer "yes" should be more than 5 questions. The number of subjects in this study who had a score of more than 5 was 29 people $(28 \%)$. It means that mental emotional disorders occurred in $28 \%$ of the research's subjects. The description of the symptoms felt by the subject is shown in table 2. 
Table 2. Symptoms felt by the subject

\begin{tabular}{|c|c|c|c|}
\hline No & Questions & Frequency & Percentage \\
\hline 1 & Do you feel tired easily? & 45 & 43,27 \\
\hline 2 & $\begin{array}{l}\text { Do you feel anxious, tense, } \\
\text { or worried? }\end{array}$ & 35 & 33,65 \\
\hline 3 & $\begin{array}{l}\text { Do you get frequent } \\
\text { headaches? }\end{array}$ & 32 & 30,77 \\
\hline 4 & $\begin{array}{l}\text { Is your digestion disturbed } \\
\text { or bad? }\end{array}$ & 29 & 27,89 \\
\hline 5 & $\begin{array}{l}\text { Do you feel tired all the } \\
\text { time? }\end{array}$ & 28 & 26,92 \\
\hline 6 & $\begin{array}{l}\text { Do you have trouble to } \\
\text { sleep? }\end{array}$ & 27 & 25,96 \\
\hline 7 & $\begin{array}{l}\text { Do you have any discomfort } \\
\text { in your stomach? }\end{array}$ & 24 & 23,08 \\
\hline 8 & $\begin{array}{l}\text { Do you find it difficult to } \\
\text { think clearly? }\end{array}$ & 20 & 19,23 \\
\hline 9 & Are you unhappy? & 20 & 19,23 \\
\hline 10 & Are you easily afraid? & 18 & 17,31 \\
\hline 11 & Do you have no appetite? & 17 & 16,35 \\
\hline 12 & Do you cry more often? & 16 & 15,38 \\
\hline 13 & $\begin{array}{l}\text { Do you find it difficult to } \\
\text { enjoy daily activities? }\end{array}$ & 14 & 13,46 \\
\hline 14 & $\begin{array}{l}\text { Are you having a hard time } \\
\text { making decisions? }\end{array}$ & 14 & 13,46 \\
\hline 15 & Are your hands trembling? & 12 & 11,54 \\
\hline 16 & $\begin{array}{l}\text { Is your daily work } \\
\text { interrupted? }\end{array}$ & 7 & 6,73 \\
\hline 17 & $\begin{array}{l}\text { Have you lost interest in } \\
\text { many things? }\end{array}$ & 7 & 6,73 \\
\hline 18 & Do you feel worthless? & 7 & 6,73 \\
\hline 19 & $\begin{array}{l}\text { Are you unable to do useful } \\
\text { things in life? }\end{array}$ & 4 & 3,85 \\
\hline 20 & $\begin{array}{l}\text { Do you have any thought to } \\
\text { end your life? }\end{array}$ & 1 & 0,96 \\
\hline
\end{tabular}

The most common symptoms felt by the subjects were feeling tired easily (43\%), followed by feeling anxious, tense, and worried (35\%), and frequent headaches $(32 \%)$. There was a subject who had thought of suicide $(0.9 \%)$.

\subsection{Factors Associated with Emotional Mental Disorders}

Characteristic factors were analyzed to determine the possible relationship with the subjects' mental emotional disorders. The results of the analysis were shown in Table 3.
Table 3. Analysis of the subjects' characteristics and mental emotional disorders

\begin{tabular}{|c|c|c|c|c|c|}
\hline \multirow{3}{*}{ Characteristics } & \multicolumn{4}{|c|}{ Emotional Disorders } & \multirow{3}{*}{$\mathrm{p}$} \\
\hline & \multicolumn{2}{|c|}{ No } & \multicolumn{2}{|c|}{ Yes } & \\
\hline & N & $\%$ & $\mathrm{~N}$ & $\%$ & \\
\hline Age (years old) & & & & & $>0.05$ \\
\hline$<20$ & 2 & 100,0 & 0 & 0,0 & \\
\hline $21-30$ & 6 & 66,7 & 3 & 33,3 & \\
\hline $31-40$ & 20 & 71,4 & 8 & 28,6 & \\
\hline $41-50$ & 39 & 79,6 & 10 & 20,4 & \\
\hline $51-60$ & 8 & 50,0 & 8 & 50,0 & \\
\hline Occupation & & & & & $>0.05$ \\
\hline Unemployed & 44 & 74,6 & 15 & 25,4 & \\
\hline Employed & 31 & 68,9 & 14 & 31,1 & \\
\hline Sex & & & & & $>0.05$ \\
\hline Male & 5 & 83,3 & 1 & 16,7 & \\
\hline Female & 70 & 71,4 & 28 & 28,6 & \\
\hline Education & & & & & $<0.05 *$ \\
\hline Elementary & 4 & 44,4 & 5 & 55,6 & \\
\hline Junior High & 16 & 61,5 & 10 & 38,5 & \\
\hline High School & 45 & 81,8 & 10 & 18,2 & \\
\hline College/University & 10 & 71,4 & 4 & 28,6 & \\
\hline Marital Status & & & & & $>0.05$ \\
\hline Not Married & 3 & 75,0 & 1 & 25,0 & \\
\hline Married & 70 & 72,2 & 7 & 27,8 & \\
\hline Widow/er & 2 & 66,7 & 1 & 33,3 & \\
\hline Salary (IDR) & & & & & $>0.05$ \\
\hline$<1.500 .000$ & 44 & 69,8 & 9 & 30,2 & \\
\hline $1.500 .000-3.500 .000$ & 22 & 68,8 & 0 & 31,3 & \\
\hline$>3.500 .000$ & 9 & 8,7 & 0 & 0,0 & \\
\hline Number of Children & & & & & $>0.05$ \\
\hline 0 & 5 & 71,4 & 2 & 28,6 & \\
\hline 1 & 22 & 78,6 & 6 & 21,4 & \\
\hline 2 & 37 & 71,2 & 5 & 28,8 & \\
\hline 3 & 9 & 64,3 & 5 & 35,7 & \\
\hline 4 & 2 & 66,7 & 1 & 33,3 & \\
\hline
\end{tabular}

The factors related to the subjects' mental emotional disorders were analyzed among the characteristics of the subjects, namely age, gender, education, occupation, income, and number of children. The results of the analysis of the factors of age, sex, occupation, income, and number of children showed a value of $p>0.05$. It means that there is no statistically significant relationship between these factors and mental emotional disorders. Only the educational factor that has p-value of $<0.05$. Thus, the educational factor has a statistically significant relationship with mental emotional disorders. Subjects with low education have a greater risk of experiencing mental emotional disorders.

\section{DISCUSSION}

Data collection was carried out at the NCD-integrated health care post, a community unit that has a role in 
conducting early detection and monitoring risk factors of non-communicable diseases in an integrated, routine, and periodic manner. This is a form of community enforcement that is developed into community-based health efforts under the guidance of Community Health Centre. The existence of the facility is expected to carry out prevention and control through early detection, monitoring, and early follow-up of risk factors for noncommunicable diseases. Mental emotional disorders often have comorbidity with non-communicable diseases, such as Diabetes Mellitus, Hypertension, and other NCDs. The screening of mental emotional disorders is in line with the goals of prevention and early detection of non-communicable diseases. Therefore, it is necessary to have this screening as part of routine activities in the facility. ${ }^{[8]}$

From the screening held in the research locations, it was found that 29 people were diagnosed with having mental emotional disorders (28\%). This result is assessed from the total SRQ score which is more than 5. This result is similar to some previous studies on the incidence of mental emotional disorders in several different populations. The results of the previous research on the elderly population showed a higher figure, in which $51 \%$ of the elderly in India experienced common mental health disorders. ${ }^{[9]}$ The results showed different values in different populations. Emotional mental disorders amounted $0.17 \%$ for junior high school students, and $79.5 \%$ for new students. ${ }^{[10][11]}$

The results showed that the most common symptom felt by subjects was fatigue, $29,7 \%$ of the subjects. Other symptoms experienced by the subjects were anxiety, tension, and headache. The three most common symptoms are in line with a study which was carried out to the students, those were the somatic symptoms in the form of headaches, anxiety symptoms in the form of difficulty in sleeping, and decreasing energy in the form of fatigue. ${ }^{[12]}$ A study also explained that anxiety disorders were characterized by a feeling of fear, worry, and being threatened. ${ }^{[13]}$ This condition is an unpleasant emotional response to various kinds of stressors, both clear and unidentified. Meanwhile, WHO also explained that depressive disorder is a general mental disorder characterized by disturbances in feelings or mood, loss of interest or pleasure, feeling of guilt or low self-esteem, insomnia, decreasing appetite, low energy, and poor concentration. WHO further mentioned that in severe conditions, depression can trigger a person to commit suicide. ${ }^{[14]}$

The result of this research showed that there was a subject who had thoughts of suicide. Even though there is only one person, this is a serious problem that requires appropriate intervention. Another study to the students as the population showed a higher rate $(7.33 \%)$ of subjects who have the desire to commit suicide. ${ }^{[2]}$ The idea to commit suicide is related to the depressive condition experienced by a person. In a study, it was found that the fearlessness of dying, self-sacrifice, and pathological externalization are characteristics. Between those two, they covered each other. The study also explained in more detailed that the common treatment for clients with suicide attempts is to control depression to predict the idea to commit suicide. ${ }^{[15]}$

Most of the participants in the NCD-integrated health care post were women, so that $90 \%$ of the subjects in this study were also women. Men rarely attend, partly because the implementation is in the morning or evening when most of them are still at work. Male participants who attended were no longer work. There was no statistically significant relationship between the sex of the subject and mental emotional disorders. The same results were obtained in research on the elderly population which concluded that there was no relationship between mental emotional disorders and gender. ${ }^{[12]}$ This result is different from the result of previous research which stated that women experience mental emotional disorders more than men. ${ }^{[16]}$ Other studies had also shown that gender differences can affect reactions to acute or chronic stress, the likelihood of becoming depressed, the memory of emotional events, strategies for dealing with the environment, and various other aspects of behavior. ${ }^{[17]}$

Pradono stated that women have a greater risk of mental emotional disorders than men. ${ }^{[18]}$ This is in line with the results of research by Chew et al. in Malaysia which reported that the incidence of distress and an increase in psychosocial problems occurred mostly in women, $52.9 \% .{ }^{[19]}$ Research conducted by Chong et al. with the theme of a survey based on mental disorders reported that the incidence of mental emotional disorders also occurred in women $(50.1 \%) .{ }^{[20]}$ Other studies of the student population have also shown that women are at greater risk of developing emotional mental symptoms. Depression in adolescents is more common in women and this pattern continues into adulthood. ${ }^{[3]}$ This difference may be due to the fact that the subject is predominantly female, so there is a tendency for the data to be only in one group, which causes no variation in the data. Different results were concluded in the studies by Chairurrijal et al. on student population which mentioned a significant relationship between gender and mental emotional disorders. However, the relationship is different from other studies, in which female subjects have a greater chance of preventing the occurrence of mental emotional disorders than men. It means that women experience fewer mental emotional disorders. ${ }^{[21]}$

The participants of this research were people aged 1559 years. Elderly people are not included. The elderly performs health monitoring through the elderly care facility. Most of the subjects in this study were 41-50 
years old. This result is different from the results of the 2013 Basic Health Research data analysis which stated that the frequency distribution of respondents in 15-24 year age category is $27.05 \%$ at most. ${ }^{[20]}$ There is no statistically significant relationship between age and the incidence of mental emotional disorders. This is not in accordance with the research of mental emotional disorder symptoms in Indonesian population which stated that age has a very strong relationship with emotional mental disorders, especially the elderly (more than 65 years). ${ }^{[2]}$ Other research also stated that mental emotional disorders in the elderly are greater at $72.7 \%{ }^{[12]}$ That result was gathered from the elderly group, while the subjects of this study were 15-59 years old people, excluding the elderly group.

Other studies on the adolescent population concluded that there is a significant relationship between age and mental emotional disorders. ${ }^{[21]}$ This is in line with the results of research by Chew et al. in Malaysia which reported that the incidence of distress and an increase in psychosocial problems occurred at an average age of 56.9 years. ${ }^{[19]}$ The research conducted by Chong et al. which was a survey on mental disorders reported that the incidence of mental emotional disorders occurred in the $35-49$ years old group $(35.8 \%){ }^{[20]}$

Most of the subjects are married. An only small proportion is unmarried and widows/ widowers. There is no statistically significant relationship between marital status and the incidence of mental emotional disorders. The result of this study is different from the previous studies which concluded that there is a significant relationship between marital status and mental emotional disorders. Subjects who are married have a greater chance of preventing the occurrence of mental emotional disorders than subjects who are not married. ${ }^{[21]}$ Other studies showed the opposite result, such as the research by Chew et al. which reported that the incidence of distress and an increase in psychosocial problems occurred in $79.1 \%$ of married subjects. ${ }^{[19]}$ Chong et al. in a survey based on mental disorders, also reported that the incidence of mental emotional disorders in married subjects was $69.4 \% .^{[20]}$

The level of subjects' education is mostly high school. Only small proportion has a higher level of education. There is a statistically significant relationship between the level of education and the incidence of mental emotional disorders. The result showed that subjects with low education had a higher incidence of mental emotional disorders. Low education is associated with an increased risk of developing mental emotional disorders and depression. ${ }^{[20]}$ Research has the same result as a study conducted by Pradono which stated that subjects with low education have a greater risk of mental emotional disorders than those with high education. ${ }^{[18]}$
Research on the adolescent population also showed a significant relationship between education level and mental emotional disorders, but the result was different. The result of the study showed that respondents with higher education levels are almost 5 times greater at risk of mental emotional disorders than those with low level of education. ${ }^{[21]}$ Research conducted by Chong et al. with the theme of mental disorder-based survey reported that the incidence of mental emotional disorders occurred in secondary education (29.9\%) followed by higher education $(20.3 \%) .{ }^{[20]}$ Other studies on the elderly population had obtained different results, that there is no relationship between education with the incidence of mental emotional disorders. ${ }^{[12]}$ The results of other studies indicated a relationship, but the relationship is different from this study. Research by Suyoko stated that a high level of education can result in better socioeconomic conditions and more stable independence. ${ }^{[16]}$ Also in a study conducted in a sub-district in Semarang in 1992, information was found that the level of education is directly proportional to people's health level. ${ }^{[2]}$ Thus, people with higher education experience less mental emotional disorders.

There are more research subjects who do not have a job than those who have one. There is no statistically significant relationship between work and the incidence of mental emotional disorders in this study. The result of this study is different from the previous research which stated that there is a relationship between work status and mental emotional disorders. ${ }^{[21]}$ People who do not work have a greater risk of mental emotional disorders than people who work. A survey conducted by Chong et al. reported that the incidence of mental emotional disorders occurred in unemployment by $23.7 \%$. $^{\text {[20] }}$

Most of the income of the subjects is still below the minimum wage of the research area. There is no statistically significant relationship between the subject's income and the incidence of mental emotional disorders. This is different from studies conducted in Brazil, where income correlates with mental health. ${ }^{[23][24]}$ Women who have less income are $1 / 6$ times $(16.7 \%)$ more likely to have major depression, generalized anxiety disorders, and common mental health disorders. ${ }^{[23]}$ Meanwhile, a study in India by Soni explained that high health costs taken from household income is related to the occurrence of common mental health disorder symptoms. ${ }^{[25]}$

Most of the subjects have 2 children. Only a small proportion of subjects who do not have children or have more than 4 children. There is no statistically significant relationship between the number of children and the incidence of mental emotional disorders. This is different from many studies related to the mental health of parents which have a correlation with children's health both physically and mentally. Vianna et al. explained that from 19 countries in the world based on the WMH survey 
conducted by WHO, 39\% of family members who suffered from both chronic diseases and mental health were reported of having burden in caring the family members. ${ }^{[26]}$ it is related to the uncompensated care by caregivers with a substantial objective and subjective burdens globally. It is also related if the parent has signs and symptoms of a mental disorders. A study by Fitzsimons in England stated that mental health problems experienced by parents are strongly related to mental health problems of their children. The correlation is higher in mother than father. ${ }^{[27]}$ This condition, which can be more generative for family having mental illness. Family members, especially children are also at risk since they are also exposed to the signs and symptoms of mental illness suffered by their parents. Leinonen in his study highlighted the quality of marital interaction and parenting. Parents who have psychosocial disorders will have less monitoring and relatively less conditioning at home to facilitate optimal growth and development of their children. ${ }^{[28]}$ This childcare capacity is associated with the worsening mental health conditions of the children both at present and in the future. Leinonen also suggested engaging in the practice of opposite-sex parenting which is important for the adjustment of children in early adolescence. ${ }^{[28]}$

Optimizing the role of the NCD-Integrated health care post (Posbindu PTM) to screen mental emotional disorders among adolescents and adults is being the key point to bridge the gap of mental health regiment in the community. Mental emotional disorders should be a concern due to their incidents as the common disorders experienced by the general population. Unmanaged mental emotional disorders will lead to worse conditions for people, their caregivers, and community as well.

\section{CONCLUSION}

Most subjects are in the age range of 41-50 years, female, unemployed, and less educated. Mental emotional disorders were experienced by $27.9 \%$ of the subjects in this study with the most symptoms was easily feeling tired. Anxiety, tension, and headache symptoms become the next common symptoms. The educational factor has a statistically significant relationship with mental emotional disorders. Subjects with low education have a greater risk of experiencing mental emotional disorders. This research also showed that there was one subject who has thought of suicide. Although only one person, this data is a serious problem that requires intervention quickly and precisely.

It is pivotal to optimize the role of the NCDIntegrated health care post (Posbindu PTM) to screen mental emotional disorders among adolescents and adults for bridging the gap of mental health regimens in the community. Providing more attention to mental emotional disorders is also important since the occurrence is massive. This should be managed accurately because mental emotional disorders prone to worsen the conditions of the people, their caregivers as well the community in general.

In this research, neither a comprehensive history nor assessments of the subjects performed, so that it became a limitation in diagnosing the clinical appropriately as SRQ cannot establish the diagnosis. It only suggests the risk, and SRQ has been recommended as a screening instrument by the WHO. Screening of mental health disorders should be performed periodically in the community and primary care. Follow-up cases and reports of mental health symptoms in the community need to be made with an integrated and responsive SOP to handle. Next research can focus on the intervention and education about mental emotional disorders, policy, community attitude toward mental health, particularly mental emotional disorders. The research should be improved more with a massive and precise outreach strategy.

\section{AUTHORS' CONTRIBUTIONS}

This study was designed and directed by W.A.P; data collection, data analysis and interpretation. Drafting the article and critical revision of the article was done by S.W. Both W.A.P and S.W. arranged the final approval of the version to be published.

\section{ACKNOWLEDGMENTS}

Authors would thank LP3M UMY. This research activity is funded by LP3M Universitas Muhammadiyah Yogyakarta. Thank you also to the NCD-Integrated health care post (Posbindu PTM), Kasihan 2 Community Health Centre which became the research site for being cooperative. The researchers hope that there will be a continuity of their activities.

\section{REFERENCES}

[1] WHO (World Health Organization), The World Health Report: Mental Health: New Understanding, New Hope, WHO Press, Geneva, 2001.

[2] S.Idaiani, Suhardi, A.Y. Kristanto, Symptom Analysis of Indonesian Mental Emotional Disorder. Majalah Kedokteran Indonesia, 2009, vol. 59(10), pp. 473-479.

[3] T. Davies, T. Craig, ABC of Mental Health, Jakarta, EGC, 2009.

[4] J.M. Donohue, H.A. Pincus. Reducing the Societal Burden of Depression: A Review of Economic Costs, Quality of Care and Effects of Treatment, Pharmaco Economics, 2007, vol. 25, pp. 7-24. 
[5] Ministry of Health Republic of Indonesia, Basic Health Research, Research and Development Bureau Jakarta, 2013.

[6] Ministry of Health Republic of Indonesia, Basic Health Research, Research and Development Bureau Jakarta, 2018.

[7] P.S. Wang, M. Land, M. Olfson, H.A. Pincus, K.B. Wells, R.C. Kessler, Twelve Month Use of Mental Health Services in the United States: Results from the National Comorbidity Survey Replication, Arch Gen Psychiatry, 2005, vol. 62, pp. 629-640.

[8] L.L. Pranandari, S.P. Arso, E.Y. Fatmasari, Analysis of Implementation of the Integrated Care Post of Non-Communicable Diseases/ Posbindu PTM in Banguntapan, Bantul, Jurnal Kesehatan Masyarakat, 2017, vol. 5(4), pp. 76-84.

[9] A. Ramalingam, S. Sarkar, K.C.Premarajan, R.P. Rajkumar, D.K. Subrahmanyam, Prevalence and Correlates of Common Mental Disorders among the Rural Elderly in Puducherry, South India: A CrossSectional Community-Based Study, 2018, International Journal of Preventive Medicine, vol. 9, pp. 1-9.

[10] R. Mubasyiroh, I.Y. Suryaputri, D.H. Tjandrarini, Determinants of Mental Emotional Symptoms of Junior and High School Students in Indonesia in 2015, Indonesian Bulletin of Health Research. 2017; vol. 45(2), pp. 103-12.

[11] G. Raval, E. Montañez, D. Meyer, E. Berger-Jenkins E. School-Based Mental Health Promotion and Prevention Program "Turn 2 Us" Reduces Mental Health Risk Behaviors in Urban, Minority Youth. Journal of School Health, 2019 vol. 89(8): pp. 662668.

[12] N. Qonitah, A.M. Isfandiari, Correlation between BWI and Physical Independence with Mental Emotional Disorder in Elderly, Jurnal Berkala Epidemiologi, 2015, vol. 3(1), pp. 1-11.

[13] I. Patimah, Suryani, A. Nuraeni, Effect of Dzikr Relaxation on Anxiety Level of Chronic Kidney Failure Patient with Hemodialysis Treatment. Jurnal Keperawatan Padjadjaran, 2015, vol. 3(1), pp.18-24.

[14] WHO (World Health Organization), Risk to Mental Health: An Overview of Vulnerabilities and Risk Factor Health: New Understanding, New Hope, WHO Press, Geneva, 2012.

[15] M.L. Rogers, I.H.Stanley, M.A.Hom, B. Chiurliza, M.C.Podlogar, T.E. Joiner, Conceptual and Empirical Scrutiny of Covarying Depression Out of Suicidal Ideation. Assessment, 2018, vol. 25(2), pp. 159-172.

[16] Suyoko, Risk Factors Related to Mental Emotional Disorders in Elderly in Jakarta (Analysis of Basic Health Research 2007), Bachelor Thesis, 2012, Faculty of Public Health Universitas Indonesia, Depok.

[17] C. Wade, C. Travis, Psychology 9th Ed, Erlangga, Jakarta.

[18] J. Pradono J., Hapsari D. \& Sari P. (2009). Kualitas Hidup Penduduk Indonesia Menurut International
Classification of Functioning, Disability, and Health (ICF) dan Faktor- Faktor yang Mempengaruhinya (Analisis Lanjut Data Riskesdas 2007), Buletin Penelitian Kesehatan.

[19] B.H.Chew, R. Vos, S. Mohd-Sidik, G.E. Rutten, Diabetes-related Distress, Depression and Distressdepression among Adults with Type 2 Diabetes Mellitus in Malaysia, PloS one, 2016, vol. 11(3), pp. $1-12$.

[20] S.A.Chong, E. Abdin , J.A.Vaingankar, D.Heng, C. Sherbourne, M.A. Yap, et al, Population-Based Survey of Mental Disorders in Singapore, 2017, vol. 1(2), pp. 49-66.

[21]Chairurrijal, A. Asnawi, Nurjannah, Marthoenis, A. Aulina, Analysis of Correlation between Disability and Mental Emotional Disorders in Aceh Province,Jurnal Ilmu Keperawatan, 2019,vol. 6(2), pp. 1-10.

[22]R.B. Darmojo, Social Gerontology: Social and Psychological Problems in Elderly in: R.B. Darmojo, H.H. Martono, Geriatry: Elderly Science. 3rd ed., Balai Penerbit FKUI, Jakarta, 2004.

[23] C.L. deMola, M.X. Carpena, H. Gonçalves, L.Q. deAvila, R. Pinheiro, J.V.M. dosSantos, B.L. Horta, How Sex Differences in Schooling and Income Contribute to Sex Differences in Depression, Anxiety and Common Mental Disorders: The Mental Health Sex-Gap in A Birth Cohort from Brazil, Journal of Affective Disorders, 2020, vol. 274, pp. 977-985.

[24] D.R. Bandeira, E.C. Azevedo, B.C. Cattani, M.A. daSilva, E.J.M.Filho, G.B. Frizzo, Factors Associated With Mental Health in Mothers with Children Under Seven, Psicothema, 2020, vol. 32(3), pp. 346-351.

[25] A. Soni, N. Fahey, N. Byatt, A. Prabhakaran, et al, Association of Common Mental Disorder Symptoms with Health and Healthcare Factors among Women in Rural Western India: Results of A Cross-sectional Survey, BMJ Open, 2016, vol. 6(7), pp. 1-8.

[26] M.C. Viana, M.J. Gruber, V. Shahly, et al, Family Burden Related to Mental and Physical Disorders in the World: Results From the WHO, World Mental Health (WMH) Surveys. Brazilian Journal of Psychiatry, 2013, vol. 35(2), pp. 115-125.

[27]E. Fitzsimons, A. Goodman, E. Kelly, J.P. Smith, Poverty Dynamics, and Parental Mental Health: Determinants of Childhood Mental Health in the UK. Social Science \& Medicine, 2017, vol. 175, pp. 43-51.

[28] J.A. Leinonen, T.S.Solantaus, R.L.Punamäki, Parental Mental Health, and Children's Adjustment: The Quality of Marital Interaction and Parenting as Mediating Factors. Journal of Child Psychology and Psychiatry, 2003, vol. 44(2), pp. 227-241. 